\title{
El alfabeto hebreo con fines específicos: la aljamía de los textos sefardíes Hebrew Alphabet for Specific Purpose: Sephardic Texts in Aljamía (Spanish in Semitic Characters)
}

\author{
Manuel Nevot Navarro, Carmen Vanesa Álvarez Rosa, Emilia Velasco Marcos, Isaac Castrillo de la Mata \\ manuelnevot@usal.es, vane@usal.es, emilia@usal.es, isaac_cdlm@usal.es. \\ Facultad de Filología \\ Universidad de Salamanca \\ Salamanca, España
}

\begin{abstract}
Resumen-Partiendo de un sucinto recorrido por la historia de la escritura, nos detenemos brevemente en los alfabetos herederos del fenicio, del que descienden las escrituras cananeas. Tras esto, damos a conocer los caracteres hebreos, especialmente aquellos empleados en los materiales impresos. En este punto, hacemos hincapié en la ausencia de signos vocálicos, rasgo distintivo de las lenguas semíticas. Una vez familiarizados con las letras hebreas, proponemos a los enseñantes que escriban con ellas sus nombres: sin saberlo, están recurriendo a la aljamía. Finalmente, comprobamos que se es capaz de leer un pequeño texto el judeoespañol para acabar con fragmentos de diversa índole.
\end{abstract}

Palabras clave: Escrituras, Alfabeto hebreo, aljamía, textos sefardíes, Propuesta docente

Abstract-After a short glance about the history of writing, we will pause concisely in the alphabets inherited from the Phoenician one, from which the Cananite writing descends. After that, we will let know Hebrew characters, especially those used in printed materials. At this point, we well stress the absence of vowel signs, a distinctive feature in Semitic Languages. Once students are familiar with Hebrew letters, we will propose trying to write their names using this alphabet: unknowingly, they will utilize the 'aljamia'. Finally, we will check if pupils can read a concise text in Sephardic in order to conclude with varied nature fragments.

Keywords: Writing. Hebrew Alphabet, Aljamía, Sephardic Texts, Teaching Proposal, Spanish Language

\section{INTRODUCCIÓN}

La práctica supresión del griego de los planes curriculares de la ESO ha producido un empobrecimiento de la riqueza cultural presente en el mundo mediterráneo, un espacio que parece haber sido exclusivamente romanizado. Desde luego, además de la escritura latina, han llegado hasta nuestros días un sinfín de trazos escriturarios, estrechamente vinculados con nuestro pasado.

Ante este vacío, proponemos esta unidad didáctica, en la que se aúnan todos los saberes propios de las ciencias humanísticas: la historia, la antropología, la lengua y la literatura.

\section{CONTEXTO}

En Historia, siempre se pone de relevancia la importancia capital que supone el nacimiento de la escritura como instrumento para testimoniar el paso del ser humano por la faz de la tierra. Sin embargo, en las aulas y en los libros de texto empleados en Bachillerato y Secundaria no se halla ninguna referencia a las diversas teorías que explican el porqué de tal descubrimiento, que sin duda supuso una revolución de gran alcance.

Por lo que respecta a la asignatura de Lengua Castellana, apenas aparecen mencionadas referencias a la variedad de los sefardíes en los recientes materiales para alumnos de primaria y secundaria, hecho que contrasta con la difusión, más o menos relevante del mundo sefardí, realizada a finales del siglo XIX, en el marco de las guerras en Marruecos y especialmente, ya en el siglo XX, con las campañas a favor de los judíos de linaje español desarrolladas por el senador Pulido (1904, 1905).

Asimismo, en la Historia de España, la imagen del judío queda totalmente distorsionada, subyugada a los estereotipos medievales, en la que escuetamente se menciona a esta minoría desempeñando las profesiones de médicos, traductores y prestamistas, amén de ser perseguidos por la Inquisición (como es bien sabido, el Santo Oficio no tenía ni competencias ni autoridad para reprender a los 'infieles').

A todo este desconocimiento, se añade la situación política actual en Oriente Medio, donde los medios de comunicación de masas suelen mostrar una clara tendencia política, en la que las razones históricas, religiosas y culturales, como tantas veces acaece, nos pueden guiar hacia una mejor comprensión del mundo en el que nos movemos.

Ante esta situación calamitosa, proponemos que cada vez son más necesarios talleres en los que humildemente se ofrezca una panorámica sobre una variante del castellano que parece relegada al olvido, mediante tanto del alfabeto hebreo como de los textos escritos en aljamía. Así, se ofrecen las herramientas con las que los estudiantes pueden acceder a las fuentes originales en judeoespañol y, en consecuencia, de la riqueza literaria que se atesora y a la que, a partir de entonces, tienen acceso. 


\section{DESCRIPCIÓN}

La secuenciación se ha establecido teniendo en cuenta los destinatarios: alumnos de colegios e institutos. Por tanto, la duración que hemos estimado tiene como meta cincuenta minutos, plazo en el que se desarrollan las clases regladas.

\section{Material necesario:}

A) Presentación de powerpoint (elaboración propia)

B) Fotocopias de alfabetos hebreos (elaboración propia)

Se ha establecido el plan de trabajo que a continuación se expone:

\section{A. El origen de la escritura (15 minutos)}

Previamente, se tantea al alumnado cuál consideran, de entre todos los inventos, como el más importante (nadie piensa en la escritura, que goza ya de una saludable antigüedad de unos 4.000 años). Se insiste en que recuerden la tradicional distinción entre historia y prehistoria.

Acto seguido, mediante una clase magistral, se abordan las diversas teorías que explican este legado así como la extensión geográfica en la que se desarrollan.

Así, se expone que, por lo que a la historia de la escritura se refiere, se fue desarrollando a lo largo de los siglos en varias fases. Al principio, aparecieron los pictogramas, dibujos que representaban realidades tangibles, como sucede con los primeros jeroglíficos egipcios (Se puede sugerir que representen el 'agua', una 'cabeza', etc.). Más tarde, fruto de la evolución propia de los pictogramas, llegaron los ideogramas, capaces de dar a entender realidades complejas como sucede con la escritura china. Por último, surgieron los sistemas fonemáticos bien de carácter silábico -como el cuneiforme sumerio (fig.1) o la escritura hierática egipcia - de carácter alfabético -como el demótico egipcio o la escritura fenicia-. Como puede comprenderse, los sistemas de escritura nacen de forma aislada por todas las partes del globo terráqueo. Por ejemplo, recuérdense los jeroglíficos mejicanos o la escritura maya, que experimenta un proceso similar al que se vive en Egipto.

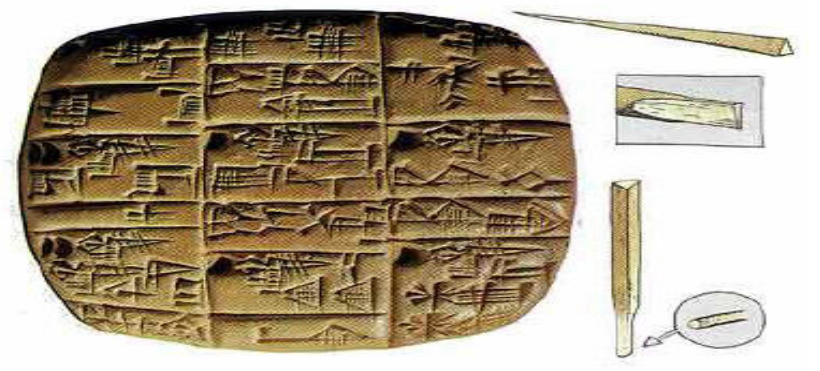

Fig. 1. Cuneiforme sumerio (Tomado de <http://4.bp.blogspot.com/_dNeihVwhgE/S_0Suc2jyeI/AAAA AAABAg/dGSasYQm9A0/s400/cuneiforme.jpg [13.12.10 21.00 GMT])

Como puede observarse, es en Egipto donde se desarrollan las diversas etapas escriturarias. De hecho, los jeroglíficos poco a poco pasan de ser meras imágenes para convertirse en ideogramas; la escritura hierática es considerada un sistema fonemático mientras que el demótico no deja de ser el primer esbozo de una escritura alfabética (fig. 2). Sin embargo, los egipcios no pudieron sistematizar, a pesar de estos primeros pasos, este incipiente alfabeto a causa de que los sacerdotes veían un riesgo para el culto la posibilidad de que cualquier individuo pudiera desvelar la verdad oculta de las letras. Esta es la razón por la que tradicionalmente los fenicios, basándose en el demótico egipcio aunque plasmado en escritura cananea, hayan pasado a la posteridad como los padres del alfabeto, al lograr crear un sistema de representación de fonemas a través de ciertos signos convencionales.

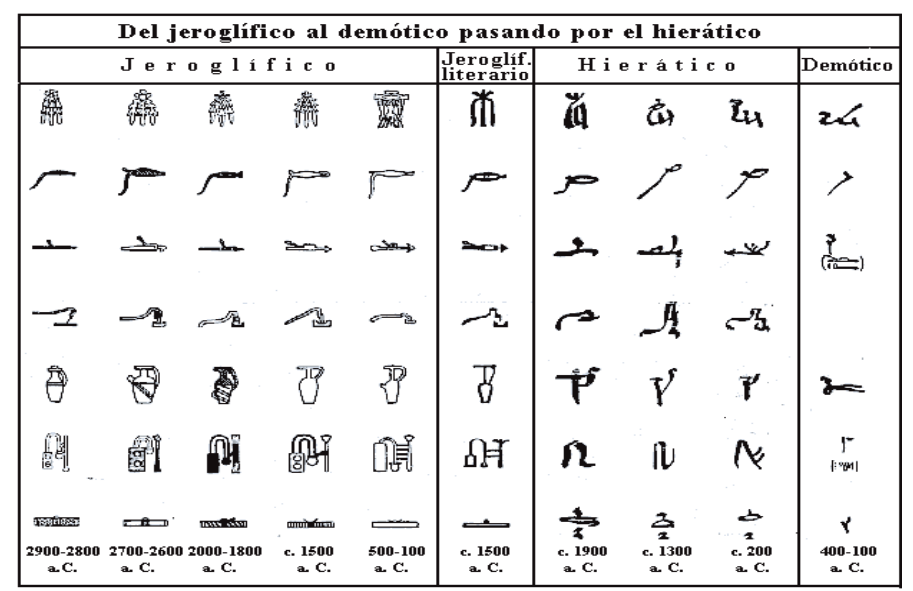

Fig. 2. Evolución de la escritura en Egipto (Tomado de $<$ http://members.tripod.com/mundo_egipcio.mx/jeroglific os.htm> [13.12.2010 20.20 GMT]

\section{B. El alfabeto hebreo (10 min)}

Por lo que respecta a las lenguas semitas, como lo son, entre otras, el arameo, el fenico, el árabe y el hebreo, todas toman de los cananeos su sistema de escritura (fig. 3 y fig. 4). De hecho, en el antiguo alfabeto hebreo se percibe una neta continuidad de las letras hebreas con los trazos cananeos. Nótese, además, cómo originariamente estos fonemas representaban imágenes (eran por tanto, pictogramas). Actualmente, el nombre de las letras hebreas recuerda estos pictogramas. A causa del destierro que somete Nabucodonosor II al pueblo judío, enviado a Babilonia, la lengua hebrea entra en contacto con el arameo. Esta es la razón por la que, de vuelta a su tierra, allá por el 539 a. C. se empiece a usar la escritura aramea. Tras unos siglos donde conviven ambos sistemas, la antigua escritura hebrea y la llamada "hebrea-aramea", esta última se impone definitivamente en el siglo II d. C. Desde entonces, este alfabeto es el empleado en hebreo principalmente en los textos impresos. Ya en plena E. Media se imita la personal forma de escribir del exegeta Rabí ShlomohYis conocida a partir de entonces como letra raši (acrónimo de su nombre), preferentemente empleada para comentarios literarios. Aparte la escritura paleohebrea, de la hebrea-aramea y de la de raši, el hebreo utiliza otro sistema de caracteres para la escritura manual, la llamada letra cursiva, que se desarrolla en la Europa del siglo XIV d.C. Hay que recordar en cualquier sistema hebreo, las consontes, como sucecede con el latín, tienen valor numérico (así, álef equivale a 1, bet a dos). 
A COMPARATIVE TABLE OF ANCIENT ALPHABETS.

\begin{tabular}{|c|c|c|c|c|c|c|c|c|c|}
\hline BEBREW. & 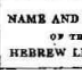 & 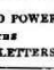 & $\begin{array}{c}\text { RAB } \\
\text { BNENIC } \\
\text { HEBREW }\end{array}$ & ARABIC. & $\begin{array}{l}\text { sama. } \\
\text { MITAN. }\end{array}$ & SYRIAC. & PHСNICLAN. & $\begin{array}{c}\text { ANCIENT } \\
\text { HEBRE W. }\end{array}$ & $\begin{array}{l}\text { ANCIENT } \\
\text { GRERK. }\end{array}$ \\
\hline$\aleph$ & Aleph & $a$ & f & 11 & $\kappa$ & 11 & $k+$ & $\nVdash$ & 4 \\
\hline 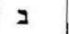 & Beth & $b$ & , & |? +ب ب ب & 9 & د ص ص & 49 & y 4 & $8 B$ \\
\hline$d$ & Gimel & $g$ & 2 & 飞 & 7 & 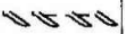 & 71 & 71 & $\langle 57\rangle$ \\
\hline 7 & Daleth & $d$ & 7 & o i & $\Phi$ & $:-$ & 49 & 94 & $\Delta \nabla P$ \\
\hline ה & $\mathrm{He}$ & $h$ & : & 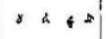 & $\approx$ & or or & 丮 & $\exists$ & 平 \\
\hline 1 & Vav & $v$ & 1 & , & 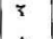 & 00 & 77 & $x$ & $F F$ \\
\hline$i$ & Zsin & $z$ & 1 & ز ز & M & $1+$ & z & $\ldots$ & $\boldsymbol{I}$ \\
\hline$\pi$ & Cheth & $c h$ & $D$ & $\tau t s>$ & $x$ & w n w N & 自曰 & 日 & 日 H \\
\hline$\theta$ & Teth & $t$ & v & $\begin{array}{ll}b & b \\
b & b\end{array}$ & $\nabla$ & 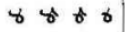 & $\theta$ & $\cdots$ & $\odot$ \\
\hline ’ & Yod & $\begin{array}{ll}y & 1\end{array}$ & ' & يا يد ي ي & $\pi t$ & $u$ u & $\pi \pi$ & $z$ & $>2$ \\
\hline 37 & Caph & $k 2$ & $=7$ & 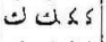 & is & $4+20$ & 794 & y & $\times k$ \\
\hline$\zeta$ & Lamed & $l \quad 3 c$ & $s$ & $j\rfloor 11$ & 2 & $v \|>>$ & $\angle \angle 4$ & $L$ & $41 \downarrow$ \\
\hline$\Delta D$ & Mem & $m \quad 4$ & no & 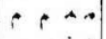 & "y & $\rho \propto ⿻ 上 丨$ & 가 4 & $y$ & $M N$ \\
\hline & Nun & $n \quad 56$ & 21 & i ن ن ن & 3 & $x+1$ & $\begin{array}{ll}4 & 4\end{array}$ & y & $N$ \\
\hline D & Samech & $s$ & $\circ$ & لـ س س س & $\beta$ & $\infty \oplus \infty \infty$ & my & $\cdots$ & +1 \\
\hline$y$ & Ain & e 7 & ע & $\varepsilon \varepsilon \times \varepsilon$ & $\nabla$ & $\Delta \|>>$ & 00 & $u$ & 0 \\
\hline$\triangle$ ๆ & $\mathrm{Pe}$ & $p \quad 8$ & 99 & ف غ غ فــ ف & $a$ & 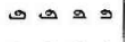 & ? & 7 & १ \\
\hline$r r$ & Tzade & $t z \quad 9$ & 11 & |صص ص & $m$ & $\begin{array}{llll}3 & 5 & 5 & 3\end{array}$ & $r r$ & $m$ & Z \\
\hline$p$ & Koph & $k 10$ & $p$ & قة قة ق ق & p & م م م مد & $P \nabla$ & 'P P & 98 \\
\hline 7 & Resh & $r 20$ & 7 & ر & 9 & ; ; & 94 & 94 & 94 \\
\hline 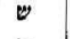 & Shin & sh 30 & $\sigma$ & شـش ش ش & $\mu$ & $\omega=\cdots$ & स\% & $w w$ & $M M$ \\
\hline$\pi$ & Tau & $t 40$ & $\Omega$ & زت تصت & s & $L A$ & $h 4$ & $x+$ & $4 T$ \\
\hline
\end{tabular}

Fig. 3. Tabla comparativa de antiguos alfabetos (Tomado de <http://hebrewresources.com/viewpage.php?page_id=38> extraída a su vez de una obra del siglo XIX [29.02.10 14:14 GMT])

\begin{tabular}{|c|c|c|c|c|c|c|}
\hline $\begin{array}{l}\text { PROTO- } \\
\text { CANAANITE }\end{array}$ & $\begin{array}{l}\text { EARLYY LE: } \\
\text { AND M }\end{array}$ & $\begin{array}{l}\text { GTFRR NAMASS } \\
\text { GEANINGS }\end{array}$ & PHOENICIAN & $\begin{array}{l}\text { EAREY } \\
\text { GREBK }\end{array}$ & $\begin{array}{l}\text { EARLY } \\
\text { MONUMENTAL. } \\
\text { LATIN }\end{array}$ & $\begin{array}{l}\text { MODERN } \\
\text { ENGLISH } \\
\text { CAPITALS }\end{array}$ \\
\hline$\delta$ & alp & oxhead & $\alpha$ & $\Delta$ & $\lambda$ & A \\
\hline$\square$ & bet & bouse & 9 & 8 & B & B \\
\hline L & samt & throwstick & 1 & 7 & $<$ & c \\
\hline$\infty$ & dieg & Ash & 9 & $\Delta$ & D & D \\
\hline 果 4 & $h(3)$ & $\operatorname{man}$ calling & $\lambda$ & $\exists$ & $E$ & $\mathbf{E}$ \\
\hline \multirow[t]{2}{*}{9} & (n) & mace & $Y$ & 7 & $\kappa$ & F \\
\hline & $\theta x(n)$ & $?$ & $I$ & $I$ & & \\
\hline \multirow[t]{2}{*}{ III } & be(c) & fence? & F & 日 & $\mathrm{H}$ & $\mathbf{H}$ \\
\hline & teres & spindle? & $\otimes$ & $\otimes$ & & \\
\hline h & sad & arm & $z$ & 2 & 1 & $\mathbf{I}$ \\
\hline (11) & kapp & paim & $x$ & $x$ & $K$ & K \\
\hline 0 & tamd & ox-goud & $c$ & 1 & $L$ & L \\
\hline$m$ & memm & water & $y$ & $\eta$ & $M$ & $M$ \\
\hline$m$ & mans & snake & 4 & $y$ & $\sim$ & $\mathbf{N}$ \\
\hline$a$ & $c^{2 n}$ & eye & 0 & 0 & 0 & 0 \\
\hline 4 & $p r^{\prime}$ & cornet? & 7 & 7 & $r$ & $\mathbf{P}$ \\
\hline$r$ & se(d) & plant & 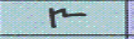 & $M$ & & \\
\hline 8 & qu(f) & $?$ & 9 & $\Phi$ & $\mathrm{O}_{2}$ & $\mathbf{Q}$ \\
\hline ? & na's. & head of man & 9 & 4 & $R$ & $\mathbf{R}$ \\
\hline$\sim$ & $\operatorname{conn}$ & composite bow & $w$ & 5 & $>$ & $s$ \\
\hline$x+$ & $\begin{array}{l}\text { is } \\
\text { (taw) }\end{array}$ & $\begin{array}{l}\text { owner's } \\
\text { mark }\end{array}$ & $x$ & $x$ & $T$ & $\mathbf{T}$ \\
\hline
\end{tabular}

Fig.4. Tabla en la que se compara la evolución del protocananeo al fenicio, y al latín y griegos antiguos. <http://faculty.maxwell.syr.edu/gaddis/hst210/sept18/default.ht $\mathrm{m}>$ [13.12.2010 21.30 GMT]

Como lengua semita, el hebreo (lo mismo sucede con el árabe), es un idioma consonántico, por lo que normalmente no emplea trazos vocálicos, es decir, se procede de la misma forma en la que los jóvenes envían guasap o mensajes de texto. Nada nuevo bajo el sol. De hecho, la introducción en el hebreo de un sistema que marque los fonemas vocálicos data del siglo
X d.C. (Sáenz-Badillos, 1988), siendo la mayor parte de los signos infralineales, es decir, se señalan los rasgos vocálicos debajo de la base consonántica, debajo del renglón de lectura. Prácticamente, las vocales -en la Edad Media divididas en largas, breves y brevísimas-, sólo se emplean en textos didácticos infantiles, poesías, rezos y palabras extranjeras. Hoy día, a pesar de los diferentes grafemas conservados, únicamente se pronuncian los fonemas /a/, /e/, /i/, / u/, precisamente la típica pronunciación sefardí, siendo esta vocalización la bese del hebreo moderno estándar (Nevot, 2015). Estamos seguros de que se puede comprender a la perfección esta frase con la que ilustramos este aspecto: «Mrcs hbl spñol bstnt bn, pr prfr mplr l ngls».

\section{Ahora os toca a vosotros (5 minutos)}

Una vez repartidas las fotocopias con los alfabetos hebreos (elaboración propia), se indica a los estudiantes que escriban su nombre propio usando la letra de imprenta (es importante saber que la orientación es de derecha a izquierda). Se recuerda que no son necesarias las vocales, aunque pueden emplearse matres lectionis, es decir, consonantes de apoyo: álef para un sonido [a], yod para representar un timbre [e, i] y waw para un fonema $[\mathrm{o}, \mathrm{u}]$. Veamos algunos nombres hispanos escritos en caracteres hebreos (tabla 1):

Tabla 1. Nombres españoles en aljamía

\begin{tabular}{|c|c|c|c|}
\hline Ángela & אנגלה & Marcos & מרקוס \\
\hline Carlos & קרלוס & Manuel & מנואל \\
\hline Emilia & אמיליה & Carmen & כרמן \\
\hline Rubén & רובן & Rosa & רוסה \\
\hline María & מאריה & Fernando & פרנאנדו \\
\hline Julio & חוליו & Aurora & אורורה \\
\hline
\end{tabular}

Aunque no sean conscientes, habrán representado sus nombres en aljamía, que, como se les ha enseñado en literatura castellana, consiste en poner la lengua romance (en nuestro caso, el castellano) en caracteres hebreos o árabes.

\section{Textos en judeo-español: lectura (10 min)}

Teniendo en cuenta que están ya capacitados para el uso y disfrute de las letras hebreas, se abre ante sus ojos todo un mundo al que hasta este momento se carecía de acceso. Huelga decir que, bien que se crea lo contrario, aún se escribe en aljamía, incluso en internet, como se observa con el texto que se presenta a renglón seguido. (Tabla 2)

Tabla 2. Texto en judeo-español

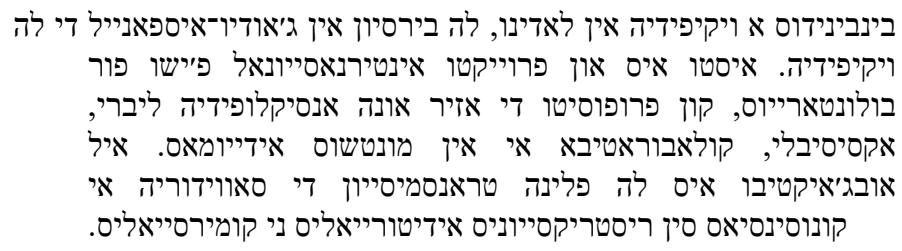

(Fragmento extraído de la Enciclopedia libre, presentando la versión en ladino o judeo-español. Consultable en: 
<http://lad.wikipedia.org/wiki/Messaje_de_Usador:Runni ngfridgesrule $>$ [13.03.2015 18: 43 GMT])

Un consejo, también aplicable a la paleografía castellana que se les dará a los alumnos es que no interrumpan la lectura y sigan leyendo para comprender el texto, ya que es probable que alguna 'palabreja' se repita a lo largo del fragmento.

\section{E. Análisis de texto (5 min)}

Por el método deductivo, se pregunta a los enseñantes, los rasgos 'lingüísticos' que presenta el fragmento de la Wikipedia que se acaba de presentar. Para ello, los alumnos han de trabajar en parejas o tríos, facilitando tres adjetivos, para una posterior puesta en común. Es previsible que salgan a colación algunas de estas opiniones:

- Arcaizante

- $\quad$ Seseante

- Interesante / Aburrido / Curioso

- Exótico

- Agotador

F. Otros ejemplos: la literatura sefardí (5 min)

Si bien se intenta difundir las literatura en judeoespañol volcándola en caracteres latinos (Romero, 2008; Romero y Moreno García, 2009; Smid, 2012) y, en consecuencia, componiendo tanto manuales, artículos y obra de difusión (Díaz-Mas, 1986; Jerusalmi, 1995; Hassán, 1995; Hassán e Izquierdo, 2008) como glosarios y diccionarios para su correcta comprensión (Nehama, [1971] 2003; Pascual Recuero, 1977; Cantera, 2004), el gran acervo sefardí permanece en caracteres hebraicos. De hecho, las actuales traducciones de los clásicos de la literatura universal todavía aparecen en versión aljamiada, ofrecida junto a la transcripción en caracteres latinos. (Fig. 5)
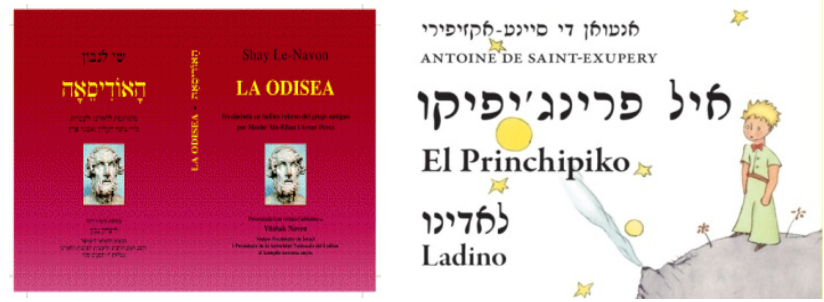

Fig. 5. Clásicos universales volcados al judeo-español a principios del siglo XXI: La Odisea traducida en 2016; El Principito, en 2010

Sin embargo, aunque parezca mentira, existía una abundante prensa en sefardí, a lo largo del siglo XIX, en ciudades como Viena y Estambul, como ilustramos (Fig. 6):

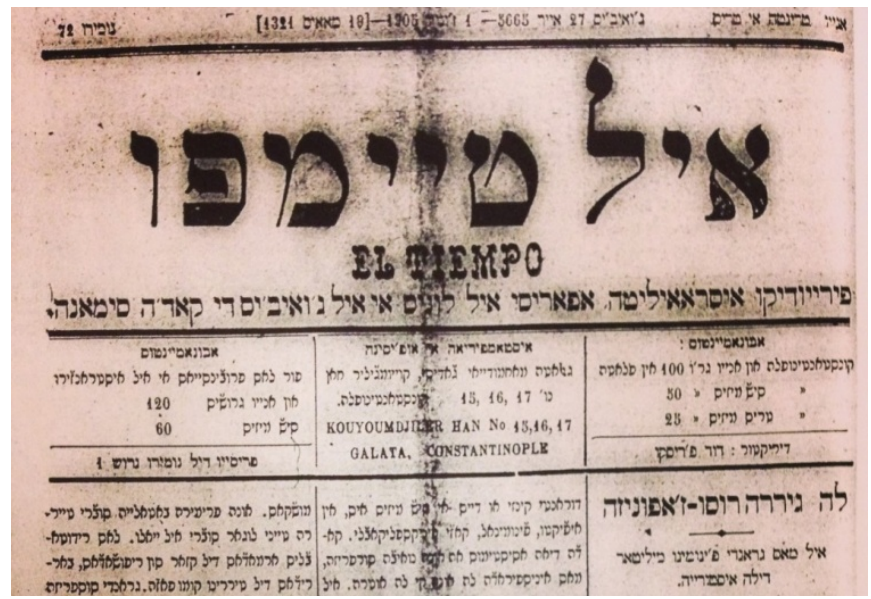

Fig. 6. Portada del periódico "El tiempo" de Constantinopla (actual Estambul)

Y desde luego, hoy como ayer, existían novelas que, adivinamos por el título, rezumaban amor, cual seriales o telenovelas actuales. (Fig. 7)

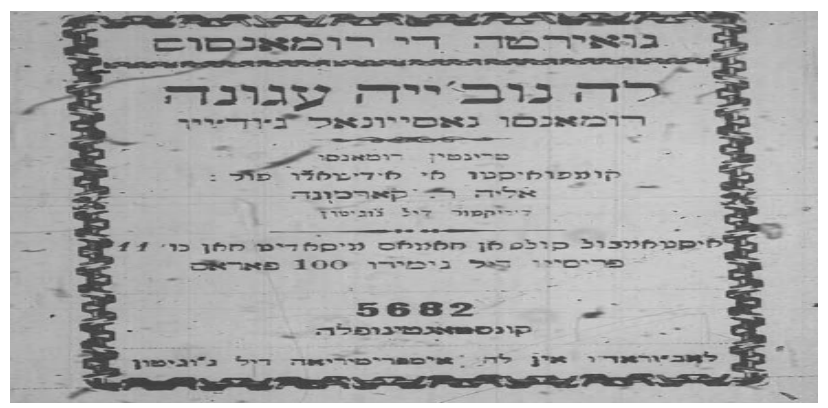

Fig. 7. La novia aguná, término hebreo con la que se designa a la mujer cuyo marido o pretendiente desaparece sin que se sepa su paradero. Romance fechado en Constantinopla en el año judío de 5682 (occidental de 1921).

$\mathrm{Y}$ en resumidas cuentas, en judeo-español se comunicaba la gente como testimonia este anuncio (Fig. 8)

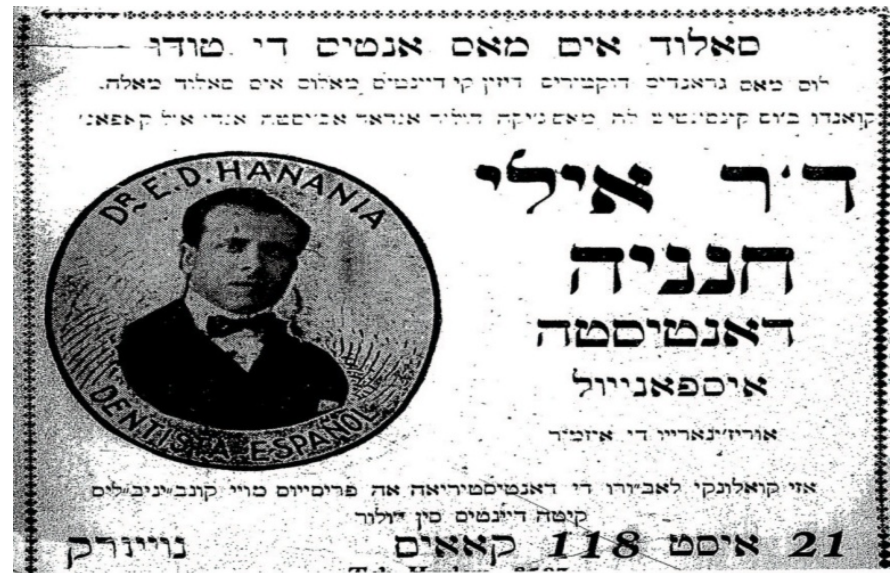

Fig. 8. Anuncio del dentista Eli Janania, en Nueva York 
La red de redes facilita además la difusión de material oral, como entrevistas, canciones y noticias en lengua sefardí. A modo de ejemplo, pueden visualizarse estos vídeos:

1. Entrevista a Moshé Shaul, profesor de la Universidad de Beersheva y exvicepresidente de la Autoridad Nasionala del Ladino, especie de Real Academia Española: $<$ https://www.youtube.com/watch?v=bgLPmM3L7m4>

2. Entrevista a Eliezer Papo, rabino, escritor y profesor de judeo-español en la Universidad de Beersheva: $<$ https://www.youtube.com/watch?v=RLqIzWvi_4c>

3. Noticias en judeo-español en la voz de Levana Dinerman, profesora de lengua sefardí en la Universidad de Tel Aviv y en el Instituto Cervantes en Israel: $<$ https://www.youtube.com/watch?v=S_K_1MkGuCk>

4. "Durme, durme” canción tradicional sefardí:

$<$ https://www.youtube.com/watch?v=a4KBwgYGVE0>

5. “Avre tu puerta cerrada”, música sefardí:

$<$ https://www.youtube.com/watch?v=_RqW_97AUUA\&inde $\mathrm{x}=8$ \&list $=$ PL40D253AB3E778010>

6. La española Ana Alcaide canta canciones sefardíes:

$<$ https://www.youtube.com/watch?v=SYy8L21HI_E>

\section{Resultados}

Dentro de las Prácticas de Difusión del Grado de Estudios Hebreos y Arameos, se realizó este taller, básicamente con los mismos parámetros aquí expuestos, para los alumnos de Bachillerato. Lamentablemente, por la brevedad de la exposición, una hora de clase, no se pudieron realizar encuestas. A título propio, el director de la escuela que nos acogió durante las Jornadas de Puertas Abiertas del centro de enseñanza fue receptivo a la iniciativa; los estudiantes se mostraron agradecidos, a pesar de las iniciales reticencias. En total, fueron dos horas lectivas en las que dimos a conocer los objetivos señalados.

\section{AGRADECIMIENTOS}

A los sefardíes, por mantenerse aferrados a una tradición y a una lengua durante más de 500 años.

A los investigadores de la cultura sefardí, para que no cejen en su empeño de difusión.

\section{REFERENCIAS}

Cantera Ortiz de Urbina, J. (2004). Diccionario Akal del Refranero Sefardí. Colección de refranes y frases hechas en judeo-español, con su correspondencia o traducción en español e inglés. Madrid: Akal.

Díaz - Mas, P. (1986). Los sefardíes: Historia, lengua y cultura. Barcelona: Riopiedras.

Hassán, I.M.e Izquierdo, R. (2008). Sefardíes: Historia de una nación dispera. Cuenca: Ediciones de la Universidad de Castilla la Mancha.

Hassán, I. M. (1995). La literatura sefadí culta: Sus principales, escritores, obras y géneros. Judíos. Sefarditas. Conversos. La expulsión de 1492 y sus consecuencias, pp. 319-330. Valladolid: Ámbito.

Nehama, J. ([1971] 2003). Dictionaire du judéo-espagnol. Madrid: Instituto “Arias Montano”.

Jerusalmi, I. (1995). El ladino: lengua del judaísmo y habla diaria. Judíos. Sefarditas. Conversos. La expulsión de 1492 y sus consecuencias, pp. 301-318. Valladolid: Ámbito.

Nevot Navarro, M. (2015). "Disensiones en el estándar del hebreo moderno”. Madrid: El Olivo XXXIX, 82, pp. 8898.

Pulido, A. ([1904] 1992). Los israelitas españoles y el idioma castellano. Barcelona: Riopiedras.

Pulido, A. ([1905] 2008). Españoles sin patria y la raza sefardí. Granada: Universidad.

Pascual Recuero, P. (1977). Diccionario básico LadinoEspañol. Barcelona: Riopiedras.

Romero, E. (2008). Entre dos (o más) fuegos: Fuentes poéticas para la historia de los sefardíes de los Balcanes. Madrid: CSIC.

Romero, E. y García Moreno, A. (2009). Dos colecciones de cuentos sefardíes de carácter mágico: Sipurénoraot y Sipurépelaot. Edición y estudio. Madrid: CSIC.

Sáenz-Badillos, A. (1988). Historia de la lengua hebrea. Sabadell (Barcelona): AUSA.

Smid, K. (2012). El sefer Mece beti, de Eliézer Papo: Ritos y costumbres sabáticas de los sefardíes de Bosnia. Madrid: CSIC. 